\title{
Technical note: The new comprehensive atmospheric chemistry module MECCA
}

\author{
R. Sander, A. Kerkweg, P. Jöckel, and J. Lelieveld \\ Air Chemistry Department, Max-Planck-Institute of Chemistry, P.O. Box 3060, 55020 Mainz, Germany \\ Received: 20 September 2004 - Published in Atmos. Chem. Phys. Discuss.: 5 November 2004 \\ Revised: 2 February 2005 - Accepted: 3 February 2005 - Published: 11 February 2005
}

\begin{abstract}
In this technical note we present the multi-purpose atmospheric chemistry model MECCA. Owing to its versatility and modular structure, it can be used for tropospheric as well as stratospheric chemistry calculations. Extending the code to other domains (e.g. mesospheric or oceanic chemistry) is easily possible. MECCA contains a comprehensive atmospheric reaction mechanism that currently includes: 1) the basic $\mathrm{O}_{3}, \mathrm{CH}_{4}, \mathrm{HO}_{\mathrm{x}}$, and $\mathrm{NO}_{\mathrm{x}}$ chemistry, 2) nonmethane hydrocarbon (NMHC) chemistry, 3) halogen $(\mathrm{Cl}$, $\mathrm{Br}$, I) chemistry, and 4) sulfur chemistry. Not only gas-phase chemistry but also aqueous-phase and heterogeneous reactions are considered. Arbitrary subsets of the comprehensive mechanism can be selected according to the research objectives. The program code resulting from the chemical mechanism can easily be used in any model, from a simple box model to a comprehensive global general circulation model.
\end{abstract}

\section{Introduction}

Many computer models of atmospheric chemistry have been developed in the past decades. Since each was aimed at a particular goal, they vary strongly in complexity and efficiency. Often they encompass the basic chemistry of $\mathrm{O}_{3}, \mathrm{CH}_{4}, \mathrm{HO}_{\mathrm{x}}$ $\left(=\mathrm{OH}+\mathrm{HO}_{2}\right)$, and $\mathrm{NO}_{\mathrm{x}}\left(=\mathrm{NO}+\mathrm{NO}_{2}\right)$. Some also include a more detailed mechanism for higher hydrocarbons, halogens, sulfur, or other species. There are box and column models as well as two- or three-dimensional regional and global models available. Chemical mechanisms have been developed for the gas phase and also for aerosols and cloud droplets. The focus is usually on either stratospheric or tropospheric chemistry. The chemistry codes are intertwined with meteorological models that supply parameters such as radiation, temperature, pressure, humidity, and wind fields.

Correspondence to: R. Sander

(sander@mpch-mainz.mpg.de)
As part of the model development, one often needs to combine several chemistry mechanisms. Another frequently occuring task is coupling chemical mechanisms to a meteorological model, for example, for an intercomparison. Unfortunately, these are both time-consuming tasks due to different approaches and incompatibilities between the codes. Also, it is often complicated because there is no clear separation between the meteorological and the chemical part of the model, and such a setup is sensitive to errors.

In our implementation we apply a new approach aimed at avoiding the above mentioned problems. Here, we present the new comprehensive and flexible atmospheric chemistry module MECCA (Module Efficiently Calculating the Chemistry of the Atmosphere).

\section{Model Description}

The main features of MECCA, as described in detail below, are:

Chemical flexibility: The chemical mechanism contains a large number of reactions from which the user can select a custom-designed subset. It is easy to adjust the mechanism, e.g. according to the latest kinetics insights.

Numerical flexibility: The numerical integration method can be chosen according to individual requirements of the stiff set of differential equations (efficiency, stability, accuracy, precision).

Modularity: Due to its modular structure and strict adherence to the MESSy standard (explained below), the code can be easily coupled to other meteorological base models (e.g. box models, 1-dimensional column models, or 3dimensional models).

Portability: The Fortran95 code is written in a portable way to allow its use on different platforms (e.g. Linux, Unix).

Availability: The code is freely available to the scientific community. 


\subsection{Chemical flexibility}

In the current version of MECCA, five previously published chemical mechanisms have been combined and updated. Tropospheric hydrocarbon chemistry is adopted from von Kuhlmann et al. (2003). The chemistry of the stratosphere is based on the model of Steil et al. (1998) and the Mainz Chemical Box Model (Meilinger, 2000). Tropospheric halogen chemistry is taken from Sander and Crutzen (1996) and von Glasow et al. (2002). The current mechanism contains 116 species and 295 reactions in the gas phase, and 91 species and 258 reactions in the aqueous phase. The rate coefficients are updated according to Sander et al. (2003), Atkinson et al. (2004), and other references. A detailed listing of reactions, rate coefficients, and their references can be found in the electronic supplement at http://www.copernicus. org/EGU/acp/acp/5/445/acp-5-445-sp.zip. It is both possible and desirable to add reactions to the mechanism in the near future. However, for computational efficiency, it is normally not required to integrate the whole mechanism. Therefore we have implemented a method by which the user can easily create a custom-made chemical mechanism. Each reaction has several labels to categorize it. For example, the labels $T r$ and $S t$ indicate reactions relevant in the troposphere and the stratosphere, respectively. These labels are not mutually exclusive. Many reactions need to be considered for both layers. There are also labels for the phase in which they occur (gas or aqueous phase) and for the elements that they contain (e.g. $\mathrm{Cl}, \mathrm{Br}$, and $\mathrm{I}$ for reactions of the halogen species). It is also possible to create new labels for specific purposes. For example, all reactions with the label $\mathrm{Mbl}$ are part of a reduced mechanism for the marine boundary layer. Using a Boolean expression based on these labels, it is possible to create custom-made subsets of the comprehensive mechanism. The main advantage of maintaining a single comprehensive mechanism is that new reactions and updates of rate coefficients need to be included only once so that they are immediately available for all subsets.

\subsection{Numerical flexibility}

Once a subset of the full mechanism has been selected as described above, the kinetic preprocessor (KPP) software (Damian et al., 2002, Sandu and Sander, in preparation, $2005^{1}$ ) is used to transform the chemical equations into Fortran 95 code. From a numerical point of view, atmospheric chemistry is a challenge due to the coexistence of very stable (e.g. $\left.\mathrm{CH}_{4}\right)$ and very reactive species, e.g. $\mathrm{O}\left({ }^{1} \mathrm{D}\right)$. To overcome the stiffness issue, associated with the large range of timescales within a single set of differential equations, robust numerical solvers are necessary. KPP provides several solvers with either manual or automatic time step control.

\footnotetext{
${ }^{1}$ Sandu, A. and Sander, R.: Technical note: Simulating chemical systems in Fortran90 and Matlab with the Kinetic PreProcessor KPP-2.0, Atmos. Chem. Phys., in preparation, 2005.
}

Although computationally more demanding, the latter are best suited for the most difficult stiffness problems e.g. associated with multiphase chemistry. For each individual application, it is necessary to balance the advantages and disadvantages regarding efficiency, stability, accuracy, and precision. We found that for most of our chemical mechanisms, Rosenbrock solvers of 2nd or 3rd order (Sandu et al., 1997) work best. However, we stress that it may be necessary to test other solvers as well to achieve the best performance for a given set of equations. Fortunately, switching between solvers is easy with KPP and does not require any reprogramming of the chemistry scheme.

There are also other numerical software packages available to integrate these stiff sets of differential equations, e.g. AutoChem (http://pdfcentral.shriver.umbc.edu/AutoChem/), Spack (Djouad et al., 2003), Chemkin (http://www. reactiondesign.com/products/open/chemkin.html), Odepack (http://www.llnl.gov/CASC/odepack/), and Facsimile (Curtis and Sweetenham, 1987). We have chosen KPP for our MECCA model because, as far as we know, it is the only program that combines the following properties:

- The generated chemistry code is suitable for integration into larger models.

- KPP is capable of producing Fortran95 code.

- KPP allows to choose between several numerical integrators.

- The code is free.

\subsection{Modularity}

An important feature of MECCA is its modular structure. Without any changes to the code, it is possible to link MECCA to different meteorological base models. This is achieved by strict adherence to the MESSy standard, as described by Jöckel et al. (2005). A major advantage of this modularity is that it allows extensive testing of the chemical mechanism in a box model before starting computationally expensive global model runs. The box models are easy to handle. All that is needed is to supply constant values or a time series for temperature, pressure, humidity, and J-values of photolysis reactions. At present, MECCA chemistry modules have been coupled to three box models and a 3-D global general circulation model. Preliminary results are shown in Sect. 3.

\subsection{Portability}

To ensure maximum portability, the code is written in standard Fortran95 (ISO/IEC-1539-1). It does not depend on any compiler-specific language extensions. We have checked this using the fortran analyser forcheck (http://www.forcheck. $\mathrm{nl} /$ ). The system requirements for the MECCA installation are: 

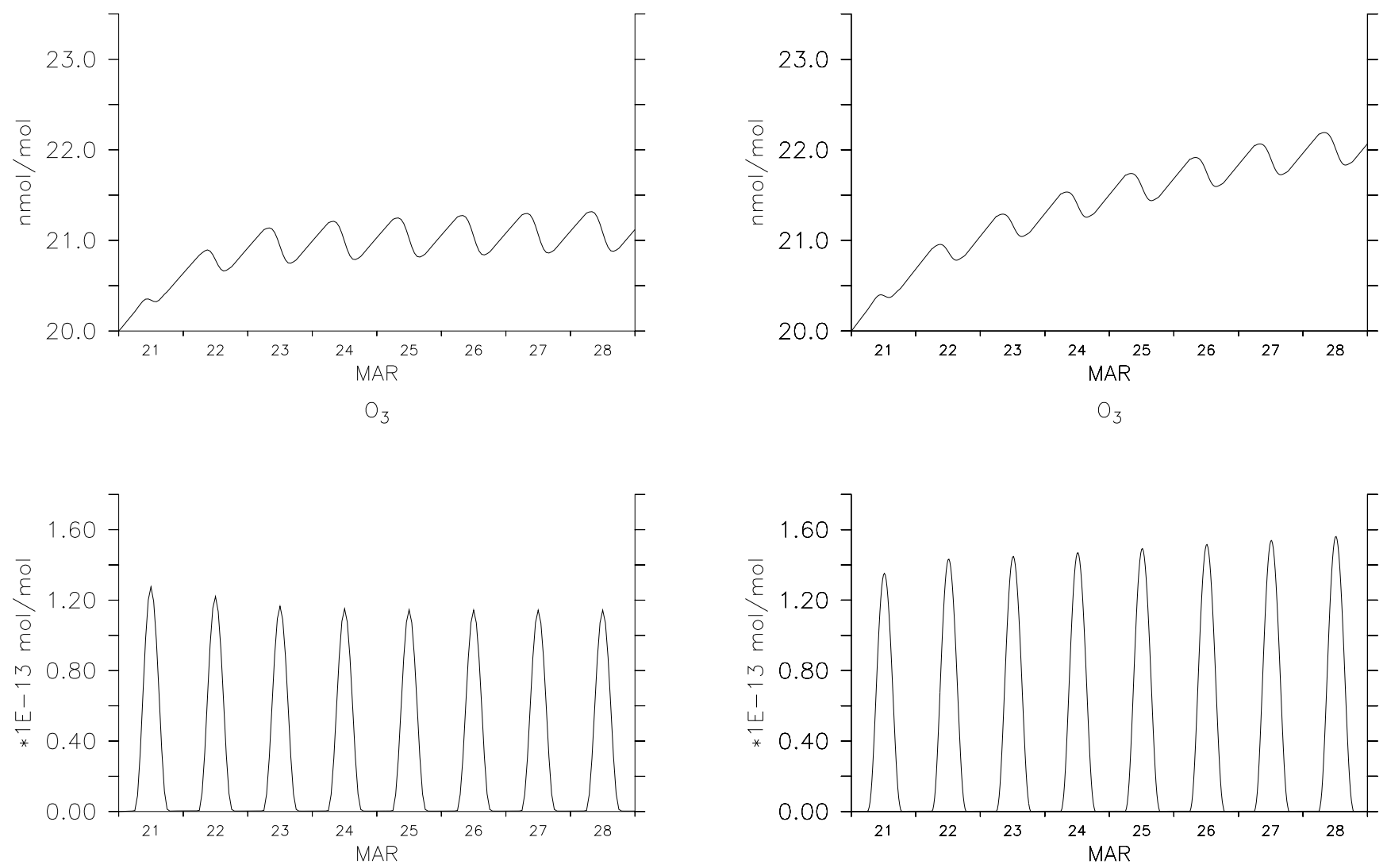

$\mathrm{OH}$
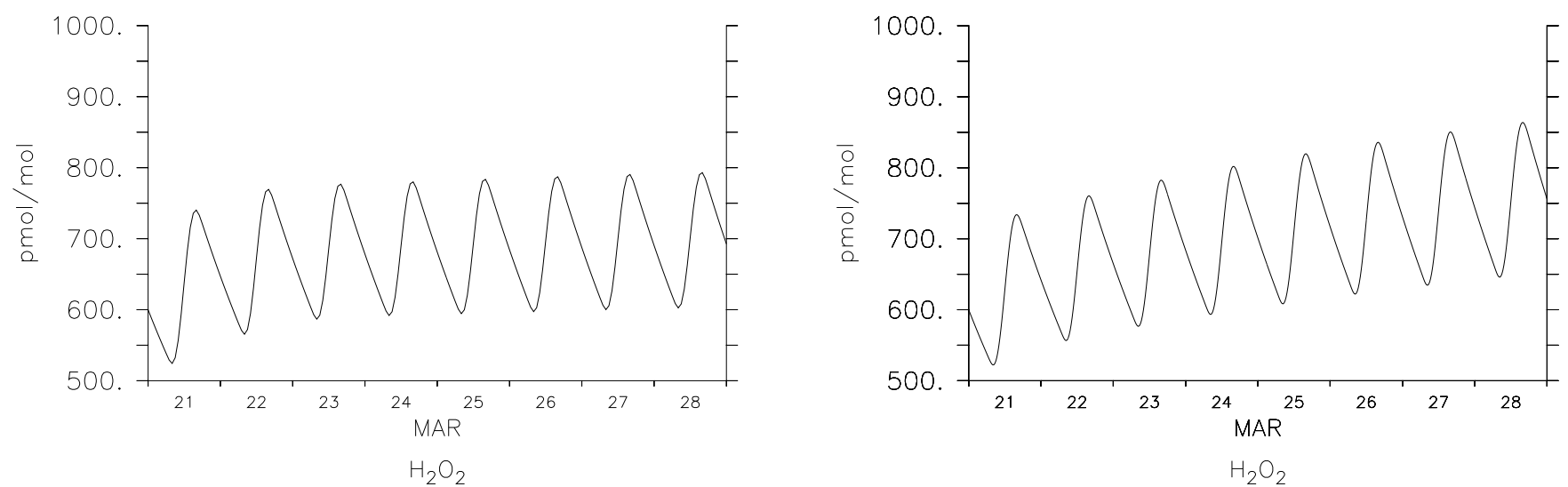

Fig. 1. Comparison of the MECCA chemistry (right column) against the Facsimile code of MOCCA (left column). As an example, the temporal evolutions of $\mathrm{O}_{3}, \mathrm{OH}$, and $\mathrm{H}_{2} \mathrm{O}_{2}$ are shown.

- A Unix or Linux operating system including the standard tools (tcsh, gawk, sed, make, etc.)

- A Fortran95 compiler (So far, we have compiled MECCA successfully with GNU, Lahey, Intel, Compaq, IBM, and NEC compilers)

- The KPP software (available in the electronic sup- plement and also at http://www.cs.vt.edu/ asandu/ Software/KPP)

- Optional: The netcdf library to obtain output files in netcdf format (without it, output is made to ascii files)

- Optional: $\mathrm{LaT}_{\mathrm{E}} \mathrm{X}$ to print a table containing the rate coefficients of the current reaction mechanism 


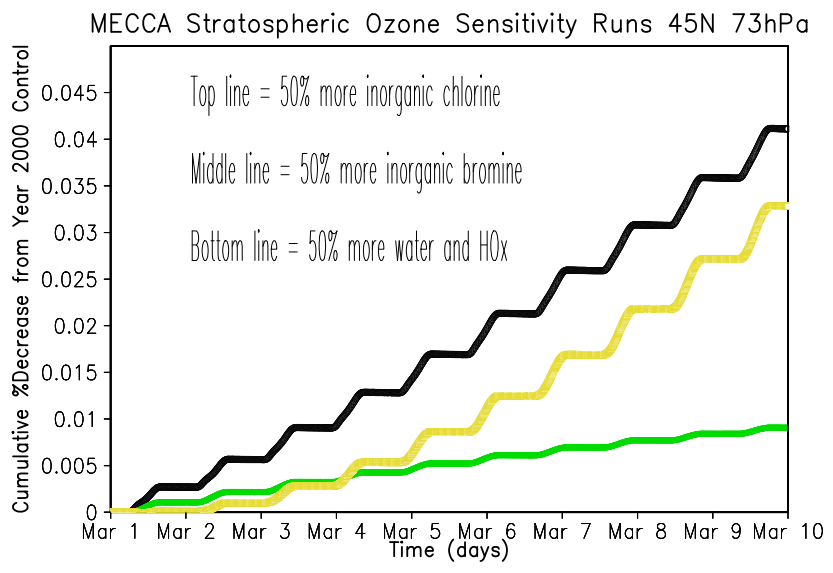

Fig. 2. Sample plot showing results of a stratospheric box model coupled to MECCA chemistry (J. L. Grenfell, pers. comm., 2004).

\subsection{Availability}

We believe that the scientific community will benefit most if MECCA is freely available. Therefore we have put the MECCA code under the GNU public licence (http://www. gnu.org/copyleft/gpl.html). We hope that this leads to a wide acceptance of MECCA as an addition or alternative to commercial software like Facsimile. We also hope for feedback from the community to maintain state-of-the-art software and chemical kinetics information. The current version is provided in the electronic supplement together with a user manual which describes how to install, execute, and modify MECCA on your computer. Future updates will be provided through our web page http://www.mpch-mainz.mpg. $\mathrm{de} / \sim$ sander/messy/mecca/ for download.

\section{Results and discussion}

To illustrate its versatility, we present here some sample applications of MECCA.

\subsection{Halogen chemistry in the marine boundary layer}

Since the reactions of our comprehensive multiphase chemistry model MOCCA (Sander and Crutzen, 1996; Vogt et al., 1996) have been implemented in MECCA, a comparison of these two models is a good start to validate MECCA. We have written a box model that provides typical conditions (temperature, pressure, humidity, sea-salt aerosol, and Jvalues of photolysis reactions) of the marine boundary layer at mid-latitude in spring, similar to MOCCA. From the comprehensive set of chemical reactions in MECCA, we discarded those that occur only in the stratosphere as well as those of higher hydrocarbons $\left(\geq C_{2}\right)$. Some results of both model runs are shown in Fig. 1. The similarity is not surprising, given the similar reaction mechanisms. It shows that

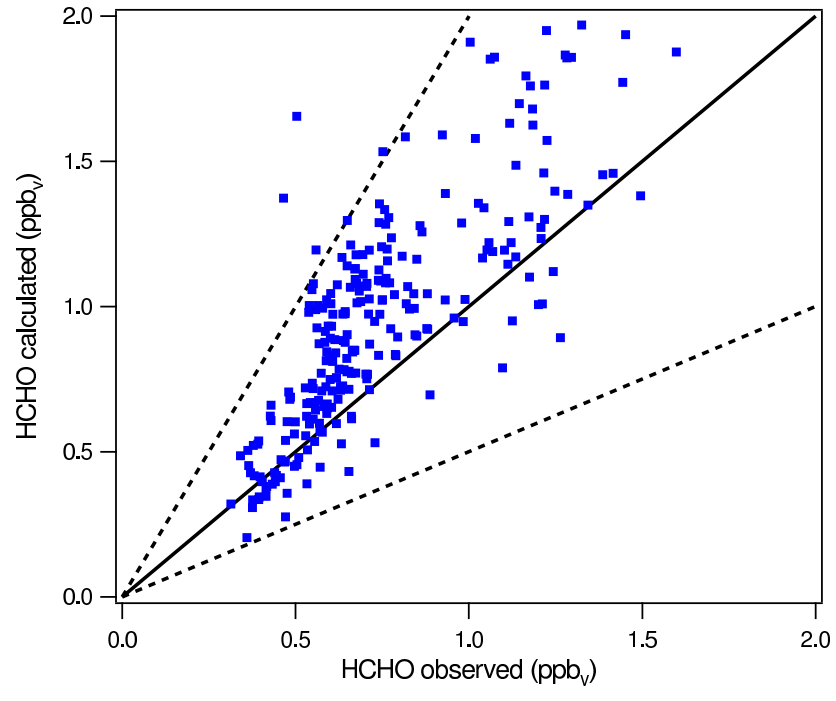

Fig. 3. Comparison between HCHO measured in the MINATROC campaign and $\mathrm{HCHO}$ calculated with MECCA (M. de Reus, pers. comm., 2004). The solid line represents the ideal 1:1 relationship. The dashed line corresponds to a deviation of a factor of two.

MECCA with its KPP integrator is capable of handling the very stiff set of differential equations and of reproducing the results of MOCCA. Minor differences result from updated rate constants and slightly different boundary conditions.

\subsection{Stratospheric chemistry}

Grenfell et al. (2004) ${ }^{2}$ have coupled MECCA to a stratospheric box model to quantify ozone loss via chemical cycles and pathways. Some results from a sensitivity study of theirs, involving the effect of increased water, chlorine and bromine upon stratospheric ozone, are shown in Fig. 2. For these calculations, tropospheric reactions were excluded.

\subsection{Modeling the field campaign MINATROC}

MECCA can also be used to compare field data with model results. De Reus et al. (2005) ${ }^{3}$ used measured data of longlived species from the MINATROC campaign as input for MECCA. For each set of measurements, the model was run until HCHO concentrations reached a steady state. The results were compared to observed values of $\mathrm{HCHO}$ as shown in Fig. 3. Only for 4 out of 272 data points is the discrepancy

\footnotetext{
${ }^{2}$ Grenfell, J. L., Lehmann, R., Mieth, P., and Langematz, U.: Chemical reaction pathways affecting stratospheric and mesospheric ozone, J. Geophys. Res., submitted, 2004.

${ }^{3}$ De Reus, M., Fischer, H., Sander, R., Gros, V., Kormann, R., Salisbury, G., van Dingenen, R., Williams, J., Zöllner, M., and Lelieveld, J.: Reduced trace gas mixing ratios in a dense Saharan dust plume, comparison of observations and photochemical boxmodel calculations, Atmos. Chem. Phys., submitted, 2005.
} 
between measured and modeled data larger than a factor of two, which is approximately the total uncertainty of all measured parameters used as input for the model calculations. Obviously, much of the measured variability in $\mathrm{HCHO}$ is associated with irregular ambient conditions, which is difficult to capture by a model. Nevertheless, the comparison in Fig. 3 suggests that systematic model biases are low.

\subsection{Global chemistry}

Box models allow quick sensitivity studies of the selected chemical mechanism. Often, however, regional or global studies are desired. Therefore we have coupled the MECCA mechanism via the MESSy interface to the general circulation model (GCM) ECHAM5 (http://www.mpimet.mpg.de/ en/extra/models/echam/echam5.php). In this setup, MECCA calculates all chemical processes, whereas the GCM integrates the non-chemical sources and sinks (e.g. advection, convection, dry deposition, sedimentation, ...) of these species. In Fig. 4 we show results to illustrate how the tropospheric halogen chemistry described above can also be applied on a global scale (Kerkweg et al., in preparation, $2005^{4}$ ). Of course, other subsets of the MECCA mechanism (e.g. stratospheric chemistry or very condensed schemes for extended climate studies) can also be selected in global applications.

\section{Conclusions}

In this technical note, we present the versatile model MECCA. Its chemical and numerical flexibility, its modularity, and its portability make it an ideal tool for many applications. The scheme is publicly available for atmospheric chemistry and climate research.

Acknowledgements. We are grateful to A. Sandu for providing the KPP software which made the development of MECCA possible. We would also like to thank R. von Glasow and R. von Kuhlmann for making their KPP chemistry codes available.

Edited by: M. Dameris

\section{References}

Atkinson, R., Baulch, D. L., Cox, R. A., Crowley, J. N., Hampson, R. F., Hynes, R. G., Jenkin, M. E., Rossi, M. J., and Troe, J.: Evaluated kinetic and photochemical data for atmospheric chemistry: Volume $\mathrm{I}$ - gas phase reactions of $\mathrm{O}_{\mathrm{x}}, \mathrm{HO}_{\mathrm{x}}, \mathrm{NO}_{\mathrm{x}}$ and $\mathrm{SO}_{\mathrm{x}}$ species, Atmos. Chem. Phys., 4, 1461-1738, 2004,

\section{SRef-ID: 1680-7324/acp/2004-4-1461.}

\footnotetext{
${ }^{4}$ Kerkweg, A. and Sander, R.: Global modeling of marine halogen chemistry with the chemistry-climate model ECHAM5/MESSy, Atmos. Chem. Phys., in preparation, 2005.
}

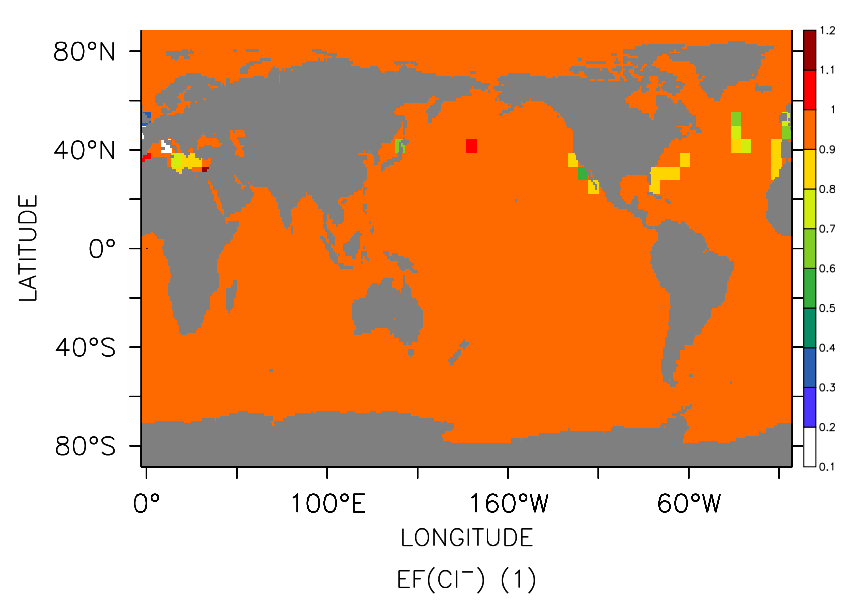

Fig. 4. Sample plot showing preliminary results of chloride enrichment factors $E F(\mathrm{Cl})$ in near-surface sea-salt aerosol. The calculations were made with the MECCA chemistry coupled to ECHAM5/MESSy. Chloride deficits (i.e. values of $E F(\mathrm{Cl})<1$ ) occur where acid displacement has transformed aerosol chloride into gaseous $\mathrm{HCl}$. This occurs mainly in areas where sea-salt aerosol mixes with anthropogenically produced acids such as $\mathrm{H}_{2} \mathrm{SO}_{4}$ and $\mathrm{HNO}_{3}$.

Curtis, A. R. and Sweetenham, W. P.: Facsimile/Chekmat User's Manual, Tech. rep., Computer Science and Systems Division, Harwell Lab., Oxfordshire, Great Britain, 1987.

Damian, V., Sandu, A., Damian, M., Potra, F., and Carmichael, G. R.: The kinetic preprocessor KPP - a software environment for solving chemical kinetics, Comput. Chem. Eng., 26, 15671579, 2002.

Djouad, R., Sportisse, B., and Audiffren, N.: Reduction of multiphase atmospheric chemistry, J. Atmos. Chem., 46, 131-157, 2003.

Jöckel, P., Sander, R., Kerkweg, A., Tost, H., and Lelieveld, J.: Technical Note: The Modular Earth Submodel System (MESSy) - a new approach towards Earth System Modeling, Atmos. Chem. Phys., 5, 433-444, 2005,

\section{SRef-ID: 1680-7324/acp/2005-5-433}

Meilinger, S. K.: Heterogeneous Chemistry in the Tropopause Region: Impact of Aircraft Emissions, Ph.D. Thesis, ETH Zürich,

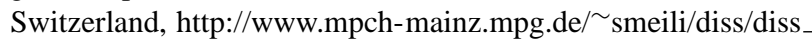
new.ps.gz, 2000.

Sander, R. and Crutzen, P. J.: Model study indicating halogen activation and ozone destruction in polluted air masses transported to the sea, J. Geophys. Res., 101D, 9121-9138, 1996.

Sander, S. P., Finlayson-Pitts, B. J., Friedl, R. R., Golden, D. M., Huie, R. E., Kolb, C. E., Kurylo, M. J., Molina, M. J., Moortgat, G. K., Orkin, V. L., and Ravishankara, A. R.: Chemical Kinetics and Photochemical Data for Use in Atmospheric Studies, Evaluation Number 14, JPL Publication 02-25, Jet Propulsion Laboratory, Pasadena, CA, 2003.

Sandu, A., Verwer, J. G., Blom, J. G., Spee, E. J., Carmichael, G. R., and Potra, F. A.: Benchmarking stiff ODE solvers for atmospheric chemistry problems II: Rosenbrock solvers, Atmos. Environ., 31, 3459-3472, 1997. 
Steil, B., Dameris, M., Brühl, C., Crutzen, P. J., Grewe, V., Ponater, M., and Sausen, R.: Development of a chemistry module for GCMs: First results of a multiannual integration, Ann. Geophys., 16, 205-228, 1998,

SRef-ID: 1432-0576/ag/1998-16-205.

Vogt, R., Crutzen, P. J., and Sander, R.: A mechanism for halogen release from sea-salt aerosol in the remote marine boundary layer, Nature, 383, 327-330, 1996. von Glasow, R., Sander, R., Bott, A., and Crutzen, P. J.: Modeling halogen chemistry in the marine boundary layer, 1. Cloud-free MBL, J. Geophys. Res., 107D, 4341, doi:10.1029/ 2001JD000942, 2002.

von Kuhlmann, R., Lawrence, M. G., Crutzen, P. J., and Rasch, P. J.: A model for studies of tropospheric ozone and nonmethane hydrocarbons: Model description and ozone results, J. Geophys. Res., 108D, doi:10.1029/2002JD002893, 2003. 